\title{
6. Readiness of students third year of medical university to understand the triage processes due to intoxication. Epidemiological survey
}

\author{
Diana A. Dimitrova, PhD' \\ ${ }^{1}$ Department of Preventive Medicine, FPH, MU-Sofia, Sofia, Bulgaria
}

Mass intoxication in Bulgaria is possible at the sites where different types and quantities of industrial toxic substances, flammable liquids, and explosive materials are manufactured, stored, and / or transported. As a result, highly toxic chemicals may be expected to be released, with the risk of intoxication to the population that has fallen into the danger zones. In Bulgaria the main risk of intoxication is that of carbon monoxide in the event of fires; and corrosive substances and petroleum products in the case of environmental pollution. Risk situations are mostly as a result of failures in technological systems of different types for the period 2012-2017 in Bulgaria in the regions of Burgas, Yambol and Haskovo are described. (1-4) Serious risk of intoxication and victims due to intoxication in the country are related to fuel transport (Photo 1.) or combustion of waste materials:

- in the village of Hitrino, at 05:37 on December 10, 2016, a freight train with propane-butane and polypropylene derailed, ignited and an explosion occurred;

- there is a leak on a propane-butane tank at Karnobat at Distributive Station on 05.08.2019.

Knowledge of triage of victims of mass intoxication is an important element in the training of medical personnel and physicians in the event of emergencies, disasters, accidents and catastrophes and begins with their training in "Disaster Medicine" in the third year at medical university in the country.

Purpose. The aim of the study is to present the readiness of the third year students of medicine to understand the triage processes suffered injuries with chemical trauma and intoxication.

Materials and methods. A survey was conducted by students of medicine in third year of study, Medical University in Sofia, winter semester, from 2016 to 2018 . The questionnaire is completed at the end of medicine of disastrous situation (MCS) training - student groups that were being educated in Bulgarian and English. A five-degree selfassessment scale was used where: 5 is "rather sufficient" and 1 is "rather insufficient". Data is processed with SPSS19 and stored electronically.

Results. The total number of students participating in the study was 1210 in three consecutive academic years. In the MCS program for the students of medicine in the MU - Sofia is included section "Medical provision of the population in cases of intoxication". The results of the survey show that this is one of the most interesting sections in the discipline. That is what almost $89 \%$ of the respondents answer. Nonetheless, more than $2 / 3$ consider it difficult to understand the clinical picture according to the degree of intoxication. (Table 1.) Over $70 \%$ of students have difficulties in understanding and interpreting specific symptoms in various intoxication. The triage of the victims of mass intoxication is defined as incomprehensible by $95 \%$ of respondents. On the other hand, students are told that they are familiar with basic principles of triage in intoxication but appreciate as "rather insufficient" $93 \%$ their knowledge of their real application in theory and practice. (Fig.1.)

Conclusions. Achieving knowledge and skills for triage is a process. In case of intoxication the triage of the victims has specific characteristics. The readiness to understand triage processes in mass intoxication is rather difficult for medical students in the third year. Continued training in module or workshop is required.

Key words: readiness, triage, mass intoxication, medical students, MCS, Bulgaria

Sources:

1.Image_7194123_126_Hitrino_Photo_Reuters

2. Risk prevention project for sustainable development of the region, cb005.1.11.047 (in BULGARIAN)

3. National programme for disaster protection 2020, (in BULGARIAN)

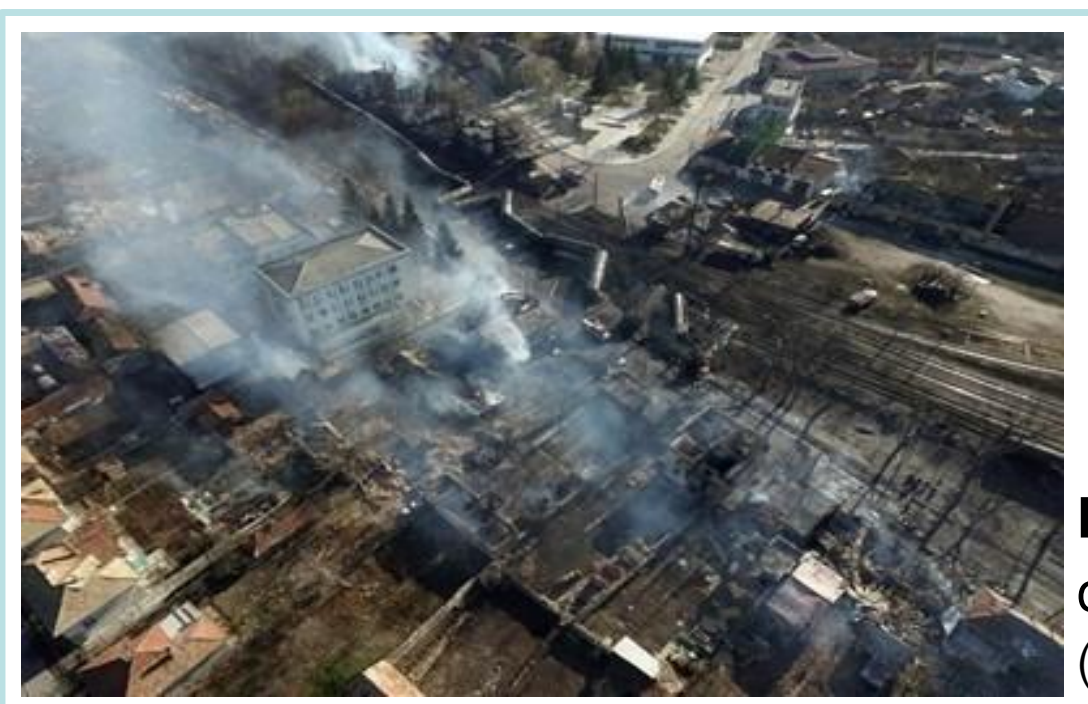

Photo 1. Hitrino, at 05:37 on December 10, 2016. (source: Reuters)

Table 1. Q19 "How difficult is it to understand:

(Indicate for each of the following by answering A1 to A5, where A5 is "the most difficult" and $\mathbf{A} \mathbf{1}$ is "the easiest)"

\begin{tabular}{|c|c|c|c|c|}
\hline & 5 is & it diffic & hd 1 is & \\
\hline & \multicolumn{2}{|c|}{$\begin{array}{l}\text { The most } \\
\text { diffcult_A5 }\end{array}$} & \multicolumn{2}{|c|}{ The easiest_A1 } \\
\hline & $\mathbf{N}$ & $\%$ & $\mathbf{N}$ & $\%$ \\
\hline Pathogenesis & 149 & $12,35 \%$ & 825 & 68,24 \\
\hline $\begin{array}{r}\text { Clinical manifestation, degree of } \\
\text { intoxication }\end{array}$ & 920 & $76 \%$ & 36 & $3 \%$ \\
\hline $\begin{array}{r}\text { Clinical manifestation, specific } \\
\text { symptoms }\end{array}$ & 859 & $71 \%$ & 88 & $7,28 \%$ \\
\hline Diagnosis & 1031 & $85,23 \%$ & 28 & $2,30 \%$ \\
\hline Protection & 293 & $24,25 \%$ & 405 & $33,45 \%$ \\
\hline First Medical Aid & 546 & $45,08 \%$ & 475 & $39,26 \%$ \\
\hline Treatment & 962 & $79,48 \%$ & 14 & $1,13 \%$ \\
\hline $\begin{array}{l}\text { Basic knowledge of the main principles of } \\
\text { triage in cases of mass intoxication }\end{array}$ & 32 & $2,60 \%$ & 1125 & $93 \%$ \\
\hline $\begin{array}{r}\text { Advance Triage in case of a chemical } \\
\text { accident }\end{array}$ & 1149 & $95 \%$ & 1 & $0,08 \%$ \\
\hline
\end{tabular}

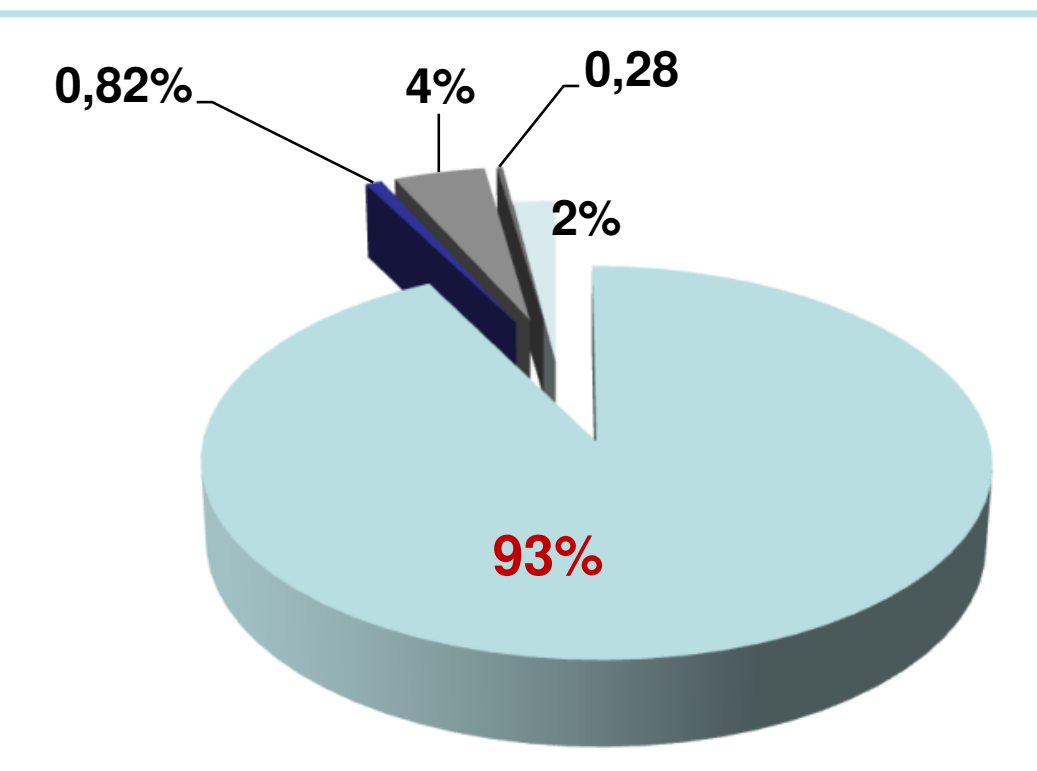

1. Rather insufficient

-2. Slightly insufficient

3. Neither sufficient nor insufficient

4. Slightly sufficient

5. Rather sufficient

Fig.1. Q20 "How do you evaluate your knowledge of triage of intoxicated people in the event of a chemical accident?"

European Resuscitation Council Congress, 19-21 September 2019, Ljubljana 